\title{
APLIKASI METODE SMOOTHING EKSPONENSIAL DALAM PERAMALAN PERSEDIAAN ENERGI LISTRIK (STUDI KASUS : PERSEDIAAN ENERGI LISTRIK OLEH PT.PLN (PERSERO) AREA MEDAN
}

\author{
Licardo H Situngkir ${ }^{1}$, Abil Mansyur ${ }^{2}$ \\ ${ }^{1,2}$ Fakultas Matematika dan Ilmu Pengetahuan Alam \\ Universitas Negeri Medan \\ E-mail : licardositungkir11@gmail.com
}

\begin{abstract}
ABSTRAK
Listrik sebagai salah satu sumber daya yang sangat penting dalam kehidupan manusia menjadi salah satu hal yang sangat diperhatikan. Hampir semua alat-alat kebutuhan manusia menggunakan tenaga listrik. Tujuan dari penelitian ini untuk mengetahui persediaan energi listrik yang terpakai dan melakukan peramalan untuk persediaan energi listrik yang akan terpakai di wilayah PT.PLN(Persero) Area Medan. Salah satu analisis deret waktu yang dipakai untuk menentukan peramalan adalah metode smoothing eksponensial ganda (metode linear satu parameter dari Brown). Data yang digunakan adalah data primer yang di ambil dari kantor cabang PT.PLN(Persero) Area Medan dengan kurun waktu Januari 2014 - Juli 2017.Langkah-langkah penelitian yang akan dilakukan adalah: Mengumpulkan data; Memplot data; Menentukan nilai smoothing eksponensial; Melakukan pemeriksaan ramalan; Menghasilkan ramalan yang akan datang; dan Membuat kesimpulan.Hasil penelitian peramalan menunjukkan bahwa peramalan persediaan energi listrik yang terpakai di wilayah PT.PLN (Persero) Area Medan untuk tahun 2018 adalah 5,84 \% untuk golongan sosial, 5,08\% untuk golongan rumah tangga, 5,38 \% untuk golongan bisnis, 12,27\% untuk golongan industri, 1,37 \% untuk golongan pemerintahan.
\end{abstract}

Kata Kunci: Metode Smoothing, Smoothing Eksponensial Ganda (Metode Linear Satu Parameter dari Brown, Listrik, Golongan Sosial, Golongan Rumah Tangga, Golongan Bisnis, Golongan Industri, Golongan Pemerintahan.

\begin{abstract}
Electricity as one of the most important resources in human life becomes one of the things that is very concerned. Almost all the tools of human need use electric power. The purpose of this research is to know the inventory of used electric energy and to forecast for the supply of electric energy that will be used in PT.PLN (Persero) Area Medan. One of the time series analyzes used to determine forecasting is the double exponential smoothing method (the linear one-parameter method of Brown). The data used is the primary data taken from the branch office PT.PLN (Persero) Medan Area with the period January 2014 - July 2017.The steps of research that will be conducted are: Collecting data; Plotting data; Specifies the exponential smoothing value; Conducting forecasting; Produce the forecast to come; and Make a conclusion.The result of forecasting research
\end{abstract}


shows that the forecasting of electricity supply that used in PT.PLN (Persero) Medan area for year 2018 is 5,84\% for social group, 5.08\% for household class, 5.38\% for business class, $12.27 \%$ for the industry, $1.37 \%$ for the governmental group.

Keywords: Smoothing Method, Multiple Exponential Smoothing (One Parameter Linear Method from Brown, Electricity, Social Group, Household Group, Business Group, Industrial Group, Governmental Groups.

\section{Pendahuluan}

Dalam kehidupan sehari-hari, manusia sebagai produsen sekaligus konsumen yang selalu berupaya untuk memenuhi kebutuhan hidupnya yang beraneka ragam. Dimulai dari pemanfaatan sumber daya alam yang tersedia hingga pendaurulangan bahan-bahan atau produk-produk bekas pakai. Sumber daya yang ada kini dimanfaatkan manusia untuk mencapai pemenuhan kebutuhan sehari-hari.

Listrik sebelum kemerdekaan dan di awal kemerdekaan sampai Tahun 1965 sejarah listrik di Sumatera Utara bukanlah hal yang baru. Kalau listrik mulai ada di wilayah Indonesia Tahun 1893 di daerah Batavia, maka 30 tahun kemudian (1923) listrik mulai ada di Medan. Sentralnya di bangun di tanah pertapakan Kantor PLN Cabang Medan yang sekarang di Jalan Listrik No.8 Medan, di bangun oleh NV NIGEM / OGEM perusahaan swasta Belanda. Kemudian menyusul pembangunan listrik di Tanjung Pura dan Pangkalan Brandan (1924), Tebing Tinggi (1927), Sibolga (NV ANIWN), Labuhan Bilik (1936) dan Tanjung Tiram (1937).

Ketidakseimbangan daya listrik antara sisi suply (penyedia listrik) dengan sisi demand (permintaan daya listrik) dapat mengakibatkan kerugian. Pada sisi pembangkit atau penyedia energi listrik(supply) dapat terjadi pemborosan apabila daya yang dihasilkan lebih besar daripada konsumsi listrik. Pada sisi konsumen (demand) apa bila daya yang dihasilkan lebih kecil dari kebutuhan listrik konsumen makan akan terjadi kekurangan listrik.

Bahwa kondisi ideal sebuah PLN adalah harus memiliki cadangan daya listrik (reserve margin) sebesar 30 persen dari beban puncak, sehingga dari kondisi yang terjadi dilapangan dugaan masalah sementara yang dapat diambil yaitu tidak efektifnya penditribusian energi listrik yang mengakibatkan kekurangan energi listrik untuk digunakan oleh masyarakat dan semakin tingginya tingkat penggunaan energi listrik oleh masyarakat wilayah PLN Area Medan. 
Dasar metode smoothing adalah pembobotan sederhana atau pemulusan observasi masa lalu dengan suatu deret berkala untuk memperoleh ramalan masa mendatang. Keuntungan utama dari metode smoothing adalah biayanya yang rendah, kemudian dalam penerapannya, dan kecepatan untuk di terima [1].

\section{Kajian Teori}

\subsection{Peramalan (Forecasting)}

Peramalan (forecasting) didefenisikan juga sebagai suatu alat bantu yang penting untuk melakukan suatu perencanaan yang efektif dan efesien. Untuk membuat suatu peramalan yang baiak, maka peramalan tersebut perlu direncanakan dan dijadwalkan sehingga akan diperlukan suatu periode waktu yang paling sedikit dalam periode waktu yang dibutuhkan untuk membuat kebijakan tersebut. Karena semakin lama kebutuhan akan peramalan bertambah dimana manajemen senantiasa melakukan pendekatan ilmiah terhadap perubahan-perubahan lingkungan. Dalam hal ini terdapat sedikit nilai, tetapi dalam kenyataan tidak ada nilai bila membuat ramalan jangka pendek sehingga efektifitas kegiatan tidak dapat diperoleh [2].

Pada Grafik 1 yang dibawah merupakan skenario peramalan. Menurut skala waktu kita berada pada suatu titik tertentu yang disebut titik refrensi, dan kita melihat kebelakang pada observasi masa lalu serta melihat kedepan pada masa mendatang. Sekali telah dipilih suatu model peramalan, kita mencocokkan model tersebut terhadap data yang diketahui dan diperoleh nilai taksiran yang sesuai (fitted values). Dengan menggunakan nilai observasi yang telah diketahui dapat dihitung nilai kesalahan pencocokan ( fitted errors), yaitu suatu ukuran kebaikan yang sesuai ( googness of fit) dari model tersebut dan bila nilai observasi yang baru tersedia, kita dapat menghitung nilai dari kesalahan peramalan (forecasting errors). Metode pemulusan yang dibahas dalam skripsi ini merupakan data yang diketahui periode per periode, sebagai kebalikan akan penggunaan data yang masa lalu dalam mencari model yang paling cocok [1].

Titik Referensi

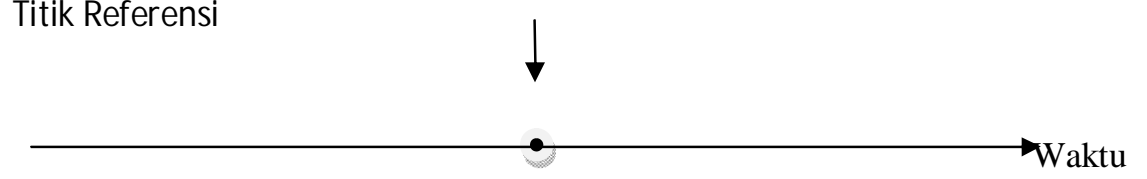

a. Data masa lalu tersedia $\mathrm{n}$ periode data

$X_{t-n+1} \ldots \ldots . . X_{t-2} X_{t-1} X_{t}$

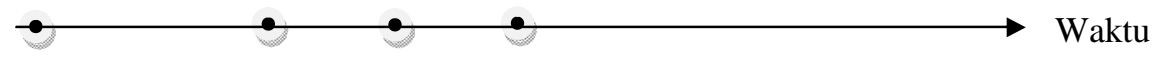


b. Diperlukan Ramalan Masa Mendatang ${ }^{\mathrm{a}} \mathrm{m}$ periode kedepan

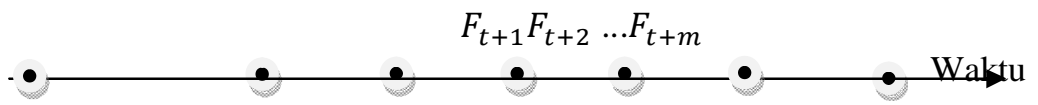

c. Nilai-nilai taksiran yang cocok dengan menggunakan suatu Model ${ }^{b}$

$$
F_{t-n+1} F_{t-2} F_{t-1} F_{t}
$$

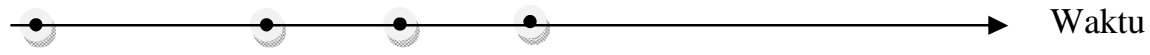

d. Kesalahan Pencocokan

$$
\left(X_{t-n+1}-F_{t-n+1}\right) \ldots \ldots . .\left(X_{t-1}-F_{t-1}\right),\left(X_{t}-F_{t}\right)
$$

e. Kesalahan Peramalan ( bilamana $X_{t+1}, X_{t+2}$ dan seterusnya menjadi ada)

$$
\left(X_{t+1}-F_{t+1}\right),\left(X_{t+2}-F_{t+2}\right)
$$

Grafik 1 Skenario Peramalan

\subsection{Metode Pemulusan (Smoothing)}

Metode smoothing (pemulusan) digunakan untuk menghilangkan atau mengurangi keteracakan (randomnes) dari suatu deret waktu. Dengan metode smoothing eksponensial, data yang dimuluskan akan menaik/menurun secara eksponensial [3].

\subsection{Metode Smoothing Eksponensial Tunggal}

Teknik pemulusan eksponensial tunggal digunakan dengan menetapkan bobot tertentu atas data yang tersedia dan berdasarkan bobot itu akan diketahui pula bobot atas hasil peramalan sebelumnya [4].(Lebrin : 2009).

Metode pemulusan eksponensial tunggal dikembangkan dari persamaan awal sebagai berikut:

$F_{t+1}=F_{t}+\left(\frac{X_{t}}{N}-\frac{X_{t-N}}{N}\right)$

Dengan:

$$
\begin{aligned}
& F_{t}=\text { Nilai ramalan pada waktu } \mathrm{t} \\
& X_{t}=\text { Data aktual pada waktu } \mathrm{t} \\
& \mathrm{N}=\text { Jumlah seluruh data }
\end{aligned}
$$




\subsection{Metode Smoothing (Pemulusan) Eksponensial Ganda (Metode Linear Satu Parameter dari Brown)}

Dengan cara analogi yang dipakai pada waktu berangkat dari rata-rata bergerak tunggal ke pemulusan (smoothing) eksponensial tunggal, dapat bergerak ke pemulusan eksponensial ganda. Dasar pemikiran dari pemulusan eksponensial linear dari Brown adalah serupa dengan rata-rata bergerak linear: karena kedua nilai pemulusan tunggal dan pemulusan ganda ketinggalan dari data yang sebenarnya bilamana terdapat unsur trend. Perbedaan antara nilai dari pemulusan (smoothing) tunggal dan pemulusan(smoothing) ganda dapat ditambahkan kepada nilai pemulusan tunggal dan disesuaikan dengan trend.

Persamaan yang tepat dipakai dalam implementasi pemulusan eksponensial linear satu parameter dari Brown adalah sebagai berikut :

$$
\begin{aligned}
& S_{t}^{\prime}=\alpha X_{t}+(1-\alpha) S_{t-1}^{\prime} \\
& S_{t}^{\prime \prime}=\alpha S_{t}^{\prime}+(1-\alpha) S_{t-1}^{\prime \prime} \\
& a_{t}=S_{t}^{\prime}+\left(S_{t}^{\prime}-S_{t}^{\prime \prime}\right)=2 S_{t}^{\prime}-S_{t}^{\prime \prime} \\
& b_{t}=\frac{\alpha}{1-\alpha}\left(S_{t}^{\prime}-S_{t}^{\prime \prime}\right) \\
& F_{t+m}=a_{t}+b_{t}(m)
\end{aligned}
$$

Keterangan:

$$
\begin{aligned}
S_{t}^{\prime}= & \text { nilai pemulusan eksponensial tunggal (singel eksponensial } \\
& \text { smoothing value) } \\
S_{t}^{\prime \prime}= & \text { nilai pemulusan eksponensial ganda (double eksponensial } \\
& \text { smoothing value) } \\
a_{t}, b_{t}= & \text { konstanta pemulusan } \\
F_{t+m}= & \text { hasil peramalan untuk periode ke depan yang diramalkan } \\
\alpha & =\text { parameter pemulusan yang besarnya } 0<\alpha<1
\end{aligned}
$$

Dalam fase peramalan, penggunaan MSE ( Mean Square Error) sebagai suatu ukuran ketepatan juga dapat menimbulkan masalah.Ukuran ini tidak memudahkan perbandingan antara deret berkala yang berbeda untuk selang waktu yang berlainan, karena ukuran ini menyangkut pengkuadratan sederetan nilai. Karena alasan tersebut dalam hubungan dengan keterbatasan MSE sebagai suatu ukuran ketepatan peramalan., maka diusulkan ukuran-ukuran alternative, yang diantaranya menyangkut kesalahan persentase, yaitu: 
1. Mean Square Error

$$
M S E=\sum_{t=1}^{n} \frac{e_{t}^{2}}{n}
$$

2. Kesalahan Persentase (Percentage Error)

$$
P E_{t}=\left(\frac{X_{t}-F_{t}}{X_{t}}\right)(100 \%)
$$

3. Nilai Tengah Kesalahan Persentase (Mean Percentage Error)

$$
M P E=\sum_{i=1}^{n} P E_{t} / n
$$

4. Nilai Tengah Kesalahan Persentase Absolut (Mean Absolute Percetage Error)

$$
M A P E=\sum_{i=1}^{n}\left|P E_{t}\right| / n
$$

\section{Metode Penelitian}

Penelitian ini dilakukan di PT.PLN (Persero) Area Medan. Jenis penelitian yang dilakukan adalah studi kasus. Adapun objek dari sumber penelitian ini adalah data persediaan energi listrik yang tepakai untuk setiap golongan mulai Tahun 2014 samapai dengan tahun 2017.Langkah-langkah pengolahan data adalah pertama-tama yaitu:

1. Pengumpulan Data, dilakukan ddengan memperoleh atau mengambil data dari PT.PLN(Persero) Area Medan dari Tahun 2014 - Tahun 2017.

2. Plot Data, Data yang terkumpul di plot dan di buat dalam bentuk gfafik Time Series.

3. Kemudian data yang diperoleh dikerjakan dengan "Metode Smoothing Eksponensial Linear Satu Parameter Dari Brown” dan di masukkan kedalam tabel di bawah ini:

\begin{tabular}{|c|l|l|l|l|l|l|}
\hline Periode & $\begin{array}{l}\text { Besar } \\
\text { energi } \\
\text { listrik }\end{array}$ & $\begin{array}{l}\text { Smoothing } \\
\text { Eksponensial } \\
\text { Tunggal }\end{array}$ & $\begin{array}{l}\text { Smoothing } \\
\text { Eksponensial } \\
\text { ganda }\end{array}$ & $\begin{array}{l}\text { Nilai } \\
a_{t}\end{array}$ & $\begin{array}{l}\text { Nilai } \\
b_{t}\end{array}$ & $\begin{array}{l}\text { Nilai } \\
\text { Ramalan } \\
\mathrm{a}+\mathrm{b}(\mathrm{m})\end{array}$ \\
\hline & $(1)$ & $(2)$ & $(3)$ & $(4)$ & $(5)$ & $(6)$ \\
\hline 1 & & & & & & \\
\hline 2 & & & & & & \\
\hline 3 & & & & & & \\
\hline. & & & & & & \\
\hline. & & & & & & \\
\hline. & & & & & & \\
\hline $\mathrm{N}$ & & & & & & \\
\hline
\end{tabular}

4. Pada tabel pengerjaan:

a. Dihitung Smoothing (pemulusan) Eksponensial Tunggal pada kolom 2 
b. Dihitung Smoothing (pemulusan) Eksponensial Ganda pada kolom 3

c. Dihitung nilai $a_{t}$ dengan rumus:

$a_{t}=s_{t}{ }^{\prime}+\left(s_{t}{ }^{\prime}-s_{t}{ }^{\prime \prime}\right) \quad=2 s_{t}{ }^{\prime}-s_{t}{ }^{\prime \prime} \quad$, pada kolom 4

d. Dihitung nilai $b_{t}$ dengan rumus:

$$
b_{t}=\frac{\alpha}{1-\alpha}\left(s_{t}{ }^{\prime}-s_{t}{ }^{\prime \prime}\right) \quad \text {, pada kolom } 5
$$

e. Maka akan diperoleh nilai peramalan dengan rumus:

$$
f_{t+m}=a_{t}+b_{t} m \quad \text {, pada kolom } 6
$$

5. Setelah tabel telah dilengkapi maka akan dicari analisis kesalahannya.

6. Prosedur diatas diulang dengan menggunakan $\alpha$ yang berbeda. Dengan menggunakan nilai $\alpha=0,1: 0,2$ : 0.3 : sampai dengan $\alpha=0,9$.

7. Dari analisis nilai kesalahan dengan menggunakan masing-masing $\alpha$. Dipilih data yang menggunakan $\alpha$ yang menghasilkan MAPE terkecil.

\section{Hasil Dan Pembahasan}

Penelitian ini menggunakan data sekunder berupa pemakaian energi listrik oleh setiap golongan setiap bulannya.Adapun yang objek penelitian pada skripsi ini adalah pemakaian listrik oleh golongan Sosial, golongan Rumah Tangga, golongan Bisnis, golongan Industri dan golongan Pemerintahan.

\subsection{Metode Smoothing Eksponensial Ganda (Metode Linear Satu Parameter dari Brown)}

Setelah data yang diperoleh di kerjakan dengan metode smoothing eksponensial ganda satu parameter dari Brown untuk masing-masing golongan maka dapat kita temukan nilai $\alpha$ (alpha) yang menghasilkan nilai MSE (Mean Square Error) yang paling kecil yang nanti nya digunakan untuk menentukan peramalan untuk selanjutnya. Sehingga di peroleh nilai $\alpha$ (alpha) untuk masing-masing golongan yaitu: golongan Sosial $(0,15)$, golongan Rumah Tangga $(0,32)$, golongan Bisnis $(0,15)$, golongan Industri $(0,35)$, golongan Pemerintahan $(0,094)$. 
KARISMATIKA

VOL. 4 NO. 1 APRIL 2018
p-ISSN : $2443-0366$

e-ISSN : 2528 -- 0279

Tabel 1. Pengerjaan Metode Smoothing Eksponensial Ganda Satu Parameter Dari Brown.

Peramalan Energi Listrik yang Terpakai untuk Golongan Sosial

\begin{tabular}{|c|c|c|c|c|c|c|c|c|}
\hline Sosial & Alpha & $\begin{array}{l}\text { Smoothing } \\
\text { Tunggal }\end{array}$ & $\begin{array}{l}\text { Smoothing } \\
\text { Ganda }\end{array}$ & $a_{t}$ & $b_{\mathrm{t}}$ & $F_{\mathrm{t}}$ & Error & $A^{\prime} 2$ \\
\hline 9.980 .957 & 0,15 & 9.980 .957 & 9.980 .957 & & & & & \\
\hline 9.630 .952 & 0,15 & 9928456,25 & 9973081,888 & 9883830,613 & $-7875,1125$ & & & \\
\hline 10.588 .449 & 0,15 & 10027515,16 & 9981246,879 & 10073783,45 & 8164,99125 & 9.875 .956 & 712.894 & 508.217 .142 .342 \\
\hline 11.183 .608 & 0,15 & 10200929,09 & 10014199,21 & 10387658,97 & 32952,33141 & 10.081 .948 & 1.101 .660 & 1.213 .653 .791 .648 \\
\hline 11.312 .092 & 0,15 & 10367603,52 & 10067209,86 & 10667997,19 & 53010,64721 & 10.420 .611 & 891.481 & 794.737 .842 .930 \\
\hline 11.289 .693 & 0,15 & 10505916,95 & 10133015,92 & 10878817,97 & 65806,06332 & 10.721 .008 & 568.685 & 323.402 .811 .595 \\
\hline 10.446 .826 & 0,15 & 10497053,3 & 10187621,53 & 10806485,08 & 54605,60753 & 10.944 .624 & -497.798 & 247.802 .883 .622 \\
\hline 10.946 .579 & 0,15 & 10564482,16 & 10244150,62 & 10884813,69 & 56529,09456 & 10.861 .091 & 85.488 & 7.308 .251 .523 \\
\hline 10.913 .602 & 0,15 & 10616850,13 & 10300055,55 & 10933644,72 & 55904,92681 & 10.941 .343 & -27.741 & 769.551 .374 \\
\hline 12.124 .713 & 0,15 & 10843029,56 & 10381501,65 & 11304557,48 & 81446,10225 & 10.989 .550 & 1.135 .163 & 1.288 .595 .838 .327 \\
\hline 11.947 .962 & 0,15 & 11008769,43 & 10475591,82 & 11541947,04 & 94090,16671 & 11.386 .004 & 561.958 & 315.797 .266 .255 \\
\hline 11.163 .953 & 0,15 & 11032046,97 & 10559060,09 & 11505033,84 & 83468,27203 & 11.636 .037 & -472.084 & 222.863 .499 .418 \\
\hline 11.198 .737 & 0,15 & 11057050,47 & 10633758,65 & 11480342,29 & 74698,557 & 11.588 .502 & -389.765 & 151.916 .842 .760 \\
\hline 10.491 .745 & 0,15 & 10972254,65 & 10684533,05 & 11259976,25 & 50774,40036 & 11.555 .041 & -1.063 .296 & 1.130 .598 .065 .977 \\
\hline 12.603 .563 & 0,15 & 11216950,9 & 10764395,73 & 11669506,08 & 79862,67818 & 11.310 .751 & 1.292 .812 & 1.671 .363 .765 .981 \\
\hline 12.245 .695 & 0,15 & 11371262,52 & 10855425,74 & 11887099,29 & 91030,01865 & 11.749 .369 & 496.326 & 246.339 .739 .412 \\
\hline 12.482 .641 & 0,15 & 11537969,29 & 10957807,28 & 12118131,3 & 102381,5317 & 11.978 .129 & 504.512 & 254.532 .047 .223 \\
\hline 11.767 .640 & 0,15 & 11572419,9 & 11049999,17 & 12094840,62 & 92191,89294 & 12.220 .513 & -452.873 & 205.093 .804 .091 \\
\hline 11.198 .217 & 0,15 & 11516289,46 & 11119942,71 & 11912636,21 & 69943,54384 & 12.187 .033 & -988.816 & 977.75 \\
\hline 12.685 .060 & 0,15 & 11691605,04 & 11205692,06 & 12177518,02 & 85749,34938 & 11.982 .580 & 702.480 & 493.478 .496 .052 \\
\hline 13.051 .075 & 0,15 & 11895525,54 & 11309167,08 & 12481883,99 & 103475,021 & 12.263 .267 & 787.808 & 620.640 .859 .327 \\
\hline 13.352 .066 & 0,15 & & & & & & & \\
\hline 13.551 .609 & 0,15 & 12329646,96 & 1156 & 13094437,82 & 134963,0929 & 12.918 .846 & 632.763 & 52.596 \\
\hline 13.403 .488 & 0,15 & 12490723,12 & 11703736,16 & 13277710,08 & 138880,0523 & 13.229 .401 & 174.087 & 30.306 .312 .234 \\
\hline 13.312 .286 & 0,15 & 12613957,55 & 11840269,37 & 13387645,74 & 136533,2092 & 13.416 .590 & -104.304 & 10.879 .352 .640 \\
\hline 12.281 .544 & 0,15 & 12564095,52 & 11948843,29 & 13179347,75 & 108573,9229 & 13.524 .179 & -1.242 .635 & 1.544 .141 .611 .474 \\
\hline 14.512 .361 & 0,15 & 12856335,34 & 12084967,1 & 13627703,59 & 136123,8078 & 13.287 .922 & 1.224 .439 & 1.499 .251 .667 .643 \\
\hline 15.404 .670 & 0,15 & 13238585,54 & 12258009,86 & 14219161,22 & 173042,7665 & 13.763 .827 & 1.640 .843 & 2.692 .364 .459 .578 \\
\hline 14.562 .991 & 0,15 & 13437246,36 & 12434895,34 & 14439597,38 & 176885,4743 & 14.392 .204 & 170.787 & 29.168 .205 .108 \\
\hline 14.619 .049 & 0,15 & 13614516,76 & 12611838,55 & 14617194,96 & 176943,2126 & 14.616 .483 & 2.566 & 6.585 .102 \\
\hline 12.394 .453 & 0,15 & 13431507,19 & 12734788,85 & 14128225,54 & 122950,2962 & 14.794 .138 & -2.399 .685 & 5.758 .488 .927 .672 \\
\hline 14.781 .793 & 0,15 & 13634050,06 & 12869678,03 & 14398422,1 & 134889,1825 & 14.251 .176 & 530.617 & 281.554 .577 .457 \\
\hline 13.955 .385 & 0,15 & 13682250,3 & 12991563,87 & 14372936,74 & 121885,8412 & 14.533 .311 & -577.926 & 333.998 .784 .675 \\
\hline 15.249 .925 & 0,15 & 13917401,51 & 13130439,52 & 14704363,5 & 138875,6457 & 14.494 .823 & 755.102 & 570.179 .667 .410 \\
\hline 13.846 .643 & 0,15 & 13906787,73 & 13246891,75 & 14566683,72 & 116452,2324 & 14.843 .239 & -996.596 & 993.203 .878 .048 \\
\hline 13.263 .019 & 0,15 & 13810222,42 & 13331391,35 & 14289053,49 & 84499,60106 & 14.683 .136 & -1.420 .117 & 2.016 .732 .145 .437 \\
\hline 13.582 .392 & 0,15 & 13776047,86 & 13398089,83 & 14154005,89 & 66698,4764 & 14.373 .553 & .791 .161 & 625.935 .879 .576 \\
\hline 12.804 .802 & 0,15 & 13630360,98 & 13432930,5 & 13827791,46 & 34840,67312 & 14.220 .704 & -1.415 .902 & 2.004 .779 .516 .120 \\
\hline 14.788 .713 & 0,15 & 13804113,78 & 13488607,99 & 14119619,57 & 55677,4926 & 13.862 .632 & 926.081 & 857.625 .770 .184 \\
\hline 14.176 .79 & 0,15 & 13860015,52 & 13544319,12 & 14175711,91 & 55711,12859 & 14.175 .297 & 1.495 & 2.234 .825 \\
\hline 14.730 .636 & 0,15 & 13990608,59 & 13611262,54 & 14369954,64 & 66943,4202 & 14.231 .423 & 499.213 & 249.213 .579 .942 \\
\hline 13.541 .755 & 0,15 & 13923280,55 & 13658065,24 & 14188495,86 & 46802,70144 & 14.436 .898 & -895.143 & 801.281 .091 .123 \\
\hline 15.082 .663 & 0,15 & 14097187,92 & 13723933,64 & 14470442,19 & 65868,40135 & 14.235 .299 & 847.364 & 718.026 .494 .912 \\
\hline & & & & & & & MSE & 760.005 .530 .862 \\
\hline
\end{tabular}




\section{Menghitung Smoothing eksponensial tunggal}

- $S_{2}^{\prime}=\alpha \mathrm{X}_{2}+(1-\alpha) S_{2-1}^{\prime}$ $S_{2}^{\prime}=0,15(9.630 .952)+(1-0,15) 9.980 .957$

$S_{2}^{\prime}=9.928 .456,25$

- $S_{3}^{\prime}=\alpha X_{3}+(1-\alpha) S_{3-1}^{\prime}$

$S_{3}^{\prime}=0,15(10.588 .849)+(1-0,15) 9.928 .456,25$

$S_{3}^{\prime}=10.027 .515,16$

- $S_{43}^{\prime}=\alpha \mathrm{X}_{43}+(1-\alpha) S_{43-1}^{\prime}$

$S_{43}^{\prime}=0,15(15.082 .663)+(1-0,15) 13.923 .280,55$

$S_{43}^{\prime}=14.097 .187,92$

Menghitung Smoothing eksponensial ganda

- $\quad \mathrm{S}_{2}^{\prime \prime}=\alpha S_{2}^{\prime}+(1-\alpha) S_{2-1}^{\prime \prime}$ $S_{2}^{\prime \prime}=0,15(9.928 .456,25)+(1-0,15) 9.980 .957$

$S_{2}^{\prime \prime}=9.973 .081,888$

- $S_{3}^{\prime \prime}=\alpha S_{3}^{\prime}+(1-\alpha) S_{3-1}^{\prime \prime}$

$S_{3}^{\prime \prime}=0,15(10.027 .515,16)+(1-0,15) 9.973 .081,888$

$S_{3}^{\prime \prime}=9.981 .246,879$

- $S_{43}^{\prime \prime}=\alpha S_{43}^{\prime}+(1-\alpha) S_{43-1}^{\prime \prime}$

$S_{43}^{\prime \prime}=0,15(14.097 .187,92)+(1-0,15) 13.658 .065,24$

$S_{43}^{\prime \prime}=13.723 .933,64$

Menghitung nilai koefisien $a_{t}$ dan $b_{t}$

- Koefisien $a_{t}$

$a_{2}=2 S_{2}^{\prime}-S_{2}^{\prime \prime}$

$a_{2}=2(9.928 .456,25)-(9.973 .081,888)$

$a_{2}=9.883 .830,62$

- Koefisien $b_{t}$

$$
b_{2}=\frac{\alpha}{1-\alpha}\left(S_{2}^{\prime}-S_{2}^{\prime \prime}\right)
$$




$$
\begin{gathered}
b_{2}=\frac{0,15}{1-0,15}(9.928 .456,25-9.973 .081,888) \\
b_{2}=-7875,1125
\end{gathered}
$$

- Koefisien $a_{t}$

$$
\begin{aligned}
& a_{3}=2 S_{3}^{\prime}-S_{3}^{\prime \prime} \\
& a_{3}=2(10.027 .515,16)-(9.981 .246,879) \\
& a_{3}=10.073 .783,441
\end{aligned}
$$

- $\quad$ Koefisien $b_{t}$

$$
\begin{aligned}
& b_{3}=\frac{\alpha}{1-\alpha}\left(S_{3}^{\prime}-S_{3}^{\prime \prime}\right) \\
& b_{3}=\frac{0,15}{1-0,15}(10.027 .515,16-9.981 .246,879) \\
& b_{3}=8164,99 \\
& \quad \vdots
\end{aligned}
$$

- Koefisien $a_{t}$

$$
\begin{aligned}
& a_{43}=2 S_{43}^{\prime}-S_{43}^{\prime \prime} \\
& a_{43}=2(14.097 .187,92)-(13.723 .933,64) \\
& a_{43}=14.470 .442,19
\end{aligned}
$$

- Koefisien $b_{t}$

$$
\begin{aligned}
b_{43} & =\frac{\alpha}{1-\alpha}\left(S_{43}^{\prime}-S_{43}^{\prime \prime}\right) \\
b_{43} & =\frac{0,15}{1-0,15}(14.097 .187,92-13.723 .933,64) \\
b_{43}=65868,401 &
\end{aligned}
$$

\section{Menentukan Nilai Peramalan}

Setelah nilai alpha yang menghasilkan nilai $M S E$ terkecil ditentukan, selanjutnya dihitung nilai ramalan untuk tahun 2018.

Dengan menggunakan rumus:

$$
F_{t+m}=a_{t}+b_{t} \mathrm{~m}
$$

Dimana $\mathrm{t}$ yang digunakan ialah $\mathrm{t}=43$ sehingga nilai $a_{t}=14.470 .442,19$ dan

$b_{t}=65.868,401$. Sehingga peramalannya seperti berikut:

Untuk $\mathrm{m}=1$

$$
F_{43+1}=a_{43}+b_{43}(1)
$$




$$
\begin{aligned}
& F_{44}=14 \cdot 470.442,19+65.868,401(1) \\
& F_{44}=14.536 .310,59
\end{aligned}
$$

Sehingga diperolah hasil peramalan nya dalam dalam tabel dibawah ini :

\begin{tabular}{|c|c|c|c|}
\hline Tahun & $\mathrm{m}$ & Bulan & $\mathrm{F}_{\mathrm{t}+\mathrm{m}}$ \\
\hline \multirow{5}{*}{2017} & 1 & Agustus & $14.536 .310,59$ \\
\hline & 2 & September & $14.602 .178,99$ \\
\hline & 3 & Oktober & $14.668 .047,39$ \\
\hline & 4 & November & $14.733 .915,8$ \\
\hline & 5 & Desember & $14.799 .784,2$ \\
\hline \multirow{12}{*}{2018} & 6 & Januari & $14.865 .652,6$ \\
\hline & 7 & Februari & 14.931 .521 \\
\hline & 8 & Maret & $14.997 .389,4$ \\
\hline & 9 & April & $15.063 .257,8$ \\
\hline & 10 & Mei & $15.129 .126,2$ \\
\hline & 11 & Juni & $15.194 .994,6$ \\
\hline & 12 & Juli & $15.260 .863,01$ \\
\hline & 13 & Agustus & $15.326 .731,41$ \\
\hline & 14 & September & $15.392 .599,81$ \\
\hline & 15 & Oktober & $15.458 .468,21$ \\
\hline & 16 & November & $15.524 .336,61$ \\
\hline & 17 & Desember & $15.590 .205,01$ \\
\hline
\end{tabular}

Tabel 2 Hasil Peramalan

Demikian juga untuk pengerjaan untuk golongan Rumah Tangga, golongan Bisnis, golongan Industri dan golongan Pemerintahan dengan Metode Smoothing Eksponensial Ganda Satu Parameter dari Brown.

\section{Kesimpulan}

Hasil penelitian peramalan menunjukkan bahwa peramalan persediaan energi listrik yang terpakai di wilayah PT.PLN (Persero) Area Medan untuk tahun 2018 adalah $5,84 \%$ untuk golongan sosial, 5,08\% untuk golongan rumah tangga, 5,38 \% untuk 
KARISMATIKA

p-ISSN : $2443-0366$

VOL. 4 NO. 1 APRIL 2018

e-ISSN : 2528 -- 0279

golongan bisnis, $12,27 \%$ untuk golongan industri, $1,37 \%$ untuk golongan pemerintahan.Bahwa pemakaian energi listrik yang paling banyak terdapat pada golongan Industri dan paling rendah terdapat pada golongan pemerintahan.

\section{DAFTAR PUSTAKA}

[1] Makridakis, S., (1990): Metode dan Aplikasi Peramalan Jilid I, Erlangga, Jakarta.

[2] Supranto, N., (2000): Metode Peramalan Kuantitatif, Renika Cipta, Jakarta.

[3] Dergison, S.,(2000): Metode Statistika untuk Bisnis dan Ekonomi, Gramedia Pustaka Utama, Jakarta.

[4] Lebrin, A., (2009): Peramalan Bisnis Edisi II, Ghalia Indonesia, Jakarta. 